\title{
Çeşitli Tekerrür Periyotları için Taşkın Debilerinin Tahmininde Farklı Olasılık Dağılımlarının Karşılaştırılması: Ceyhan Nehri Örneği
}

\author{
Evren TURHAN ${ }^{*}$, Serin DEĞERLI'², Buse DUYAN ÇULHA ${ }^{3}$
}

\begin{abstract}
$\ddot{\mathbf{O z}}$
Taşkınların neden olabileceği tahribatın önlenebilmesi için çeşitli tekerrür periyotlarına bağlı olarak debilerin tahmin edilmesi büyük önem taşımaktadır. Bu çalışmada, Ceyhan Nehri üzerinde yer alan 2004 ve 2020 nolu sırasıyla Misis ve Aslantaş akım gözlem istasyonlarına ait maksimum akım değerlerinden faydalanılmıştır. 1971-2011 yılları arasına ait 41 yıllık veriler kullanılarak 2, 5, 10, 25, 50, 100, 200, 500 ve 1000 yıl tekerrür periyoduna sahip taşkın debileri hesaplanmaya çalışılmıştır. Literatürde sıklıkla incelenen Normal, Gumbel ve Pearson Tip III olasılık dağılım fonksiyonları kullanılmış, elde edilen debilerden en uygun olanının belirlenmesi amacıyla da Kolmogorov-Smirnov testi uygulanmıştır. Sonuç olarak, fonksiyon değerlerinin birbirine oldukça yakın olduğu görülmüş, Misis ve Aslantaş istasyonları için Gumbel dağılımı sonuçlarında daha yüksek debiler gözlemlenmiştir. Uygunluk testi göz önüne alındığında ise her üç olasılık dağılımının da $\% 90$ ve $\% 95$ anlamlılık düzeylerinde kabul edilebileceği belirlenmiş; Pearson Tip III ve Gumbel dağılımlarında az da olsa bir miktar daha uyumlu sonuçlar ortaya çıktığı tespit edilmiştir.
\end{abstract}

Anahtar Kelimeler: Ceyhan Nehri, Taşkın Frekans Analizi, Olasılık Dağılım Fonksiyonları, Uygunluk Testi.

\section{Comparison of Different Probability Distributions for Estimating Flood Discharges for Various Recurrence Intervals: The Case of Ceyhan River}

\begin{abstract}
It is of great importance to estimate the flow rates depending on the various recurrence periods in order to prevent the destruction that may be caused by the flash floods. In this study, with annual maximum flow data of flow observation stations was used, numbered of 2004 and 2020 Misis and Aslantaş, respectively, located on the Ceyhan River. Using 41years of data between 1971 and 2011, flood discharges with a recurrence period of 2, 5, 10, 25, 50, 100, 200, 500 and 1000 years were tried to be calculated. Normal, Gumbel and Pearson Type III probability distribution functions, which are frequently investigated in the literature, were used, and the Kolmogorov-Smirnov test was applied to determine the most optimal distribution function. As a result, it was seen that the distribution function values were quite close to each other, and higher flow rates were specified in the Gumbel distribution results for both stations. Considering the goodnessof-fit, it has been determined that all three probability distributions could be accepted at $90 \%$ and $95 \%$ significance levels. In addition, it has been seen that the Pearson Type III and Gumbel distributions are slightly more compatible.
\end{abstract}

Keywords: Ceyhan River, Flood Frequency Analysis, Probability Distribution Functions, Goodness-of-fit Test.

\footnotetext{
${ }^{1}$ Adana Alparslan Türkeş Bilim ve Teknoloji Üniversitesi, İnşaat Mühendisliği Bölümü, Adana, Türkiye, eturhan@atu.edu.tr

${ }^{2}$ Adana Alparslan Türkeş Bilim ve Teknoloji Üniversitesi, İnşaat Mühendisliği Bölümü, Adana, Türkiye, sdegerli@atu.edu.tr

${ }^{3}$ Adana Su ve Kanalizasyon İdaresi Genel Müdürlüğü, İçme Suyu Şube Müdürlüğü, Adana, Türkiye, buseduyanculha@gmail.com
}

${ }^{1}$ https://orcid.org/0000-0002-0742-4848 ${ }^{2}$ https://orcid.org/0000-0003-0208-9152 ${ }^{3}$ https://orcid.org/0000-0002-5797-3861 


\section{Giriş}

Doğal ve antropojenik etkenler tarafından meydana gelen taşkınlar, yerküre üzerinde en hasar verici afetler arasında yer almaktadır (Özcan, 2007; Bhat ve ark., 2018; Kumar, 2019). Hızla artan nüfus ve iklim değişiklikleri nedeniyle ortalama yağışlar ve akımların artma veya azalma, taşkınların ise yıkıcı etkisinin artması beklenmektedir (Tanoue ve ark., 2016; Şen ve Aksu, 2021). Taşkınların önlenmesi kapsamında her ne kadar yapısal önemler çoğu zaman yeterli olabilmesine rağmen, hidrolik yapıların tasarımı akarsu akımının davranışına göre şekillenmektedir (Yue ve ark., 1999). Su kaynaklarının planlanması ve tasarımında, taşkınların şiddeti ve tekerrür periyodunun belirlenmesi büyük önem arz etmektedir (Üneş ve ark., 2020). Bu doğrultuda birçok yöntem değerlendirilebilmektedir. Rasyonel metot, birim hidrograf metodu ve yağış-akış modellerinin yanı sıra frekans analizi çalışmaları taşkının şiddeti ile tekerrür periyodu arasındaki ilişkiyi başarılı bir şekilde ortaya koyabilen yöntemlerden birisi olarak kabul görmektedir (Bhagat, 2017; Acharya ve Joshi, 2020). Bir akarsuya ait debi dinamiğinin zamana bağlı değişsimi frekans analizi yoluyla ortaya konulabilir (Black ve Fadipe, 2009; Bhat ve ark., 2018). Taşkın frekans analizi, bir nehir boyunca akım gözlem istasyonlarında (AGI) kaydedilmiş maksimum akım verileri ile meydana gelecek taşkınların çeşitli olasılık dağılımları yardımıyla öngörülmesidir (Chow ve ark., 1988; Ahmad ve ark., 2011). Gözlenmiş akım verileri ile olasılık dağılımı arasındaki uyumun araştırılması için hipotez testlerinden faydalanılması daha güvenilir sonuçlar elde edilebilmesini sağlamaktadır (Anlı, 2006; Baykal ve Terzi, 2017).

Taşkın debi değerlerinin tespit edilmesinde Normal, Log-Normal III, Log-Pearson III, Gamma III ve Gumbel dağılımlarından faydalanılabilmektedir. Olasılık dağılımlarının veri serisine uyumluluğu, Kolmogorov- Smirnov (K-S) testi gibi birçok uygunluk testleri ile sınanabilir (Baykal ve Terzi, 2017). Aşık ve ark. (2004) yaptıkları çalışmada Gediz Havzası üzerinde belirlenen 11 adet AGİ'nin 22 yıllık akım verilerini kullanarak 2, 5, 10, 25, 50 ve 100 yıllık tekerrüre sahip taşkın debilerini hesaplamışlardır. Normal, Log Normal, Gamma, Log Pearson Tip III ve Gumbel dağılımlarından en uygun olanının belirlenmesi için K-S testini uygulamışlardır. Söz konusu test sonucunda akım gözlem verilerine en uyumlu olasılık dağılımının Log Pearson Tip III olduğunu tespit etmişlerdir. Anlı (2006) yaptığı çalışmada Giresun Aksu Havzası'nda 39 yıllık maksimum akım verilerine en uyumlu olasılık dağılımını belirlemek için K-S testini kullanmıştır. Uyguladığı testin sonucunda y1llık maksimum akım verilerine en uyumlu dağılımın Weibull dağılımı olduğunu görmüştür. Yavuz ve Ergül (2010) ele aldıkları çalışmalarında Eskişehir Porsuk Barajı'na gelen yıllık ortalama akım değerini modellemek için Normal, Log Normal, Logistic, Gamma ve Weibull olasılık dağılımını kullanmışlardır. 33 yıllık veriye en uygun olasılık dağılımının seçilmesi açısından K-S testinin sonucunda Weibull olasılık dağılımının daha uyumlu olduğunu gözlemlemişlerdir. 
Kumanlığlu ve Ersoy (2018) gözlenmiş akım verisi bulunmayan Kızıldere için 2, 5, 10, 25, 50, 100, 500 ve 1000 yıllık tekerrüre sahip taşkın debilerini Mockus yöntemi ile hesaplamışlardır. Meteoroloji gözlem istasyonlarından aldıkları verilere en uygun olasılık dağılımının belirlenebilmesi için K-S testinden faydalanmışlardır. K-S testine göre yağış verisine en uygun olasılık dağılımının Log Pearson Tip III olduğunu belirlemişlerdir.

Sandalcı (2018) yaptığı çalışmada Sakarya Nehri’nin en önemli yan kollarından biri olan Akçay deresi için 5, 10, 25, 50, 100 ve 250 yıllık tekerrür periyotlarında taşkın debilerini elde etmek için Normal, Log Normal ve Gumbel olasılık dağ̊lımlarını kullanmıştır. En uyumlu olasılık dağılımının belirlenmesi amacıyla K-S testini tercih edip sonuç olarak Log Normal dağılımının en uyumlu olduğunu gözlemlemiştir. Saka ve ark. (2019) yaptıkları çalışmada Doğu Karadeniz Havzası'nda 2213 nolu AGI'ye ait 43 yıllık veriye en uygun olasılık dağılımını belirlemeye çalışmışlardır. Yıllık maksimum akım verilerinin Log Normal, Gamma, Ekstrem Tip-I ve Log Pearson Tip III olasılık dağılımlarının uyumunu Ki-Kare testi ile değerlendirmişlerdir. Çalışmalarının sonucu olarak en büyük uyumun Gamma dağılımı ile sağlandığını görmüşlerdir. Yılmaz ve ark. (2021) Doğu Karadeniz Havzası'nda yer alan 2215 ve 2245 nolu AGİ'lere ait taşkın frekans analizi için gerekli parametre tahmin yöntemini ve verilere en uygun olasılık dağılımını öngörmeye çalışmışlardır. 5, 10, 20, 50, 100, 200 ve 500 y1llık tekerrüre sahip taşkın debilerinin tahmini için Gamma, Weibull, Log Normal ve Normal dağılımlarından faydalanmışlar ve optimum uyumu sağlayan olasılık dağılımını seçmek için K-S testini uygulamışlardır. Sonucunda 2215 nolu istasyon için Weibull, 2245 nolu istasyon için ise Log Normal dağılımının uyumlu sonuçlar verdiğini tespit etmişlerdir.

Bu çalışmada Ceyhan Nehri üzerinde yer alan 2004 ve 2020 nolu sırasıyla Misis ve Aslantaş Akım Gözlem İstasyonu (AGİ) verileri ile taşkın frekans analizi gerçekleştirerek, 2, 5, 10, 25, 50, 100, 200, 500 ve 1000 yıl gibi çeşitli tekerrür periyotlarındaki olası taşkın debilerinin belirlenmesi amaçlanmıştır. Normal, Gumbel ve Pearson Tip III olasılık dağılım fonksiyonları kullanılmış, elde edilen debilerden en uygun olanının belirlenmesi amaciyla da Kolmogorov-Smirnov testi uygulanmıştır.

\section{Materyal ve Metot}

\section{1. Çalışma Alanı ve Akım Verileri}

Ceyhan Havzası, Türkiye'deki 26 akarsu havzasından biri olup Akdeniz Bölgesi akarsu havzaları kategorisine dahil edilmektedir (Yüce ve Eşit, 2020). Havza $21.391 \mathrm{~km}^{2}$ 'lik yağış alanı ile Türkiye yüzölçümünün \%2.7'sini kaplamaktadır (Tarım ve Orman Bakanlığı (TOB), 2018). Akdeniz ikliminin etkisinde olan Ceyhan Havzası'nda, kış mevsiminin sonlarına doğru kuvvetli yağışlar 
gözlenmektedir. Havza ile aynı ada sahip Ceyhan Nehri, Elbistan İlçesi’nin Pınarbaşı mevkisinden başlamakta, güneye doğru ilerleyerek Akdeniz'e dökülmektedir (Ayaz ve ark., 2011). Havzada en fazla taşkın ve sel kısa süren ancak şiddetli yağışların ardından oluşmaktadır (Özcan, 2006). Çalışma kapsamında, Aslantaş Barajı çıkışında yer alan mülga Elektrik İşleri ve Etüt İdaresi (EİEİ) tarafından işletilmiş olan 2020 nolu AGİ ve havzanın Akdeniz'e döküldüğü çıkış noktasından önce konumlandırılmış yine EİEİ tarafından kurulan 2004 nolu AGİ çalışma alanı olarak seçilmiştir (Şekil 1). Seçilen AGI'ler ile ilgili detaylı konum bilgileri ise Tablo 1'de verilmektedir (EİĖ̇, 2011).

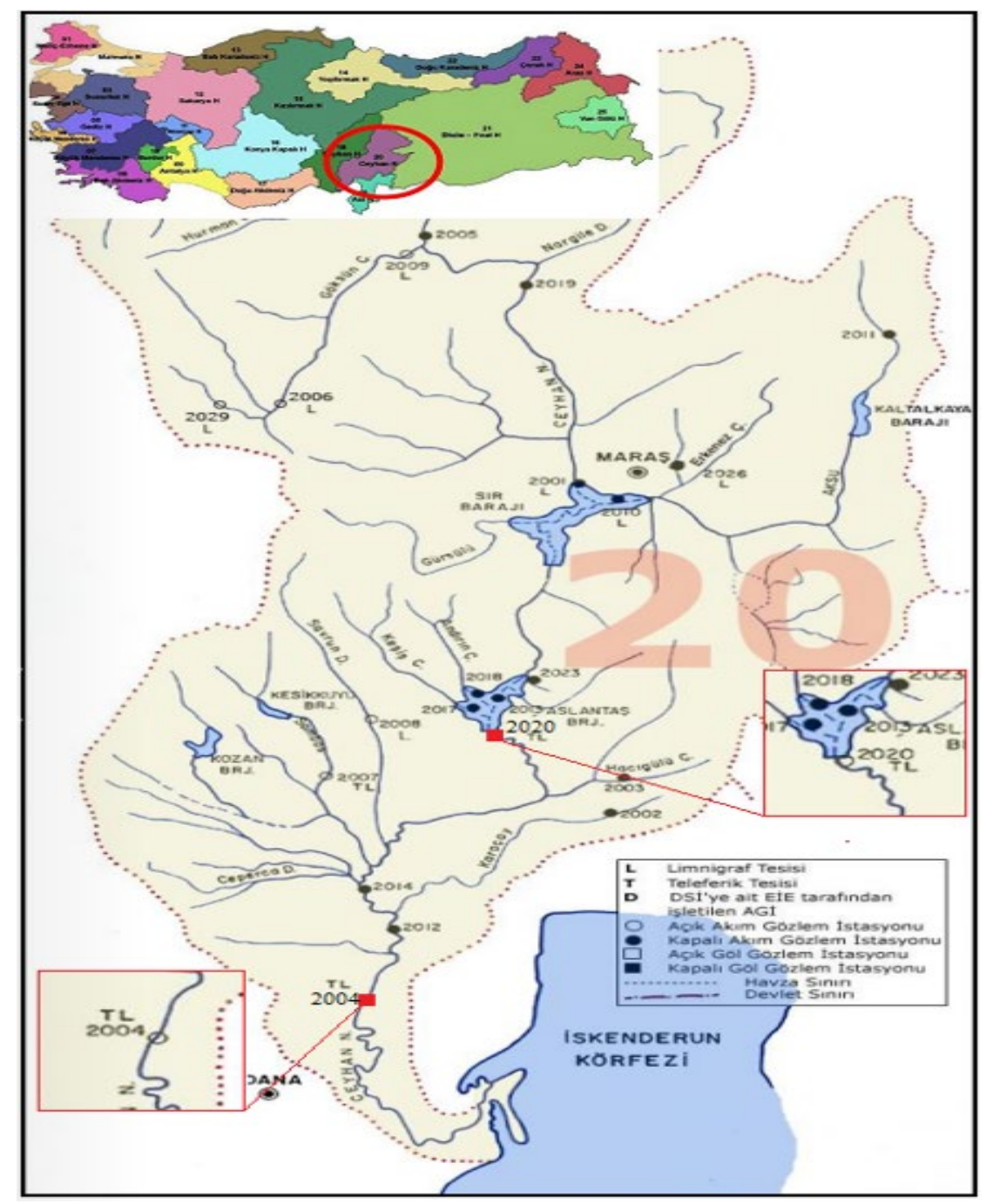

Şekil 1. 2004 ve 2020 AGİ'lerinin konumu (EİEİ, 2011)

Tablo 1. AGí Bilgileri (EIEİ, 2011)

\begin{tabular}{|c|c|c|c|c|c|c|}
\hline İstasyon No & $\begin{array}{c}\text { İstasyon } \\
\text { Adı } \\
\end{array}$ & Enlem (K) & Boylam (D) & $\begin{array}{c}\text { Yağıș Alanı } \\
\left(\mathbf{k m}^{2}\right)\end{array}$ & $\begin{array}{c}\text { Ortalama } \\
\text { Akım }\left(\mathbf{m}^{3} / \mathbf{s}\right)\end{array}$ & $\begin{array}{l}\text { Değerlendirme } \\
\text { Süresi (yıllar) }\end{array}$ \\
\hline 2004 & Misis & $36^{\circ} 57^{\prime} 38^{\prime \prime}$ & & 20.466 & 191 & 1971-2011 \\
\hline 2020 & Aslantaş & $37^{\circ} 15^{\prime} 30^{\prime \prime}$ & $36^{\circ} 16^{\prime} 35^{\prime \prime}$ & 14.708 & 168 & $1971-2011$ \\
\hline
\end{tabular}




\subsection{Taşkın Frekans Analizleri}

Belirlenen $T$ tekerrür periyoduna ait en büyük taşkın debileri rastgele değişken olarak kabul edildiği için istatistiksel yöntemler ile analiz edilmesi gerekmektedir. $T$ tekerrür periyodu, herhangi bir $x_{i}$ taşkın debisi değerinin iki kez aşılması için gereken süreyi ifade etmektedir (Baykal ve Terzi, 2017). Bu çalışmada; Ceyhan Nehri üzerinde belirlenen 2004 ve 2020 nolu AGİ'lerin taşkın debilerinin belirlenmesinde Normal, Gumbel ve Pearson Tip III dağılımlarından faydalanılmıştır.

\subsubsection{Normal Dağılım}

Normal dağılım (Gauss Dağılımı); rastgele değişkenin ortalaması $\mu_{\mathrm{x}}$ ve standart sapması olmak üzere iki parametre ile tanımlanmaktadır ve kısaca $N\left(\mu, \sigma^{2}\right)$ şeklinde ifade edilebilir. Normal dağılım fonksiyonu analitik olarak oluşturulamamaktadır ancak sayısal integrasyon ile hesaplanarak normal dağılım tabloları ile bulunabilmektedir (Bayazıt ve Oğuz, 2005). Dağılıma ait olasılık yoğunluk fonksiyonu Denklem (1) ile ifade edilmektedir (Kumanlığlu ve Ersoy, 2018).

$$
f(x)=\frac{1}{\sigma_{x} \sqrt{2 \pi}} e^{-\frac{\left(x-\mu_{x}\right)^{2}}{2 \sigma_{x}^{2}}}
$$

Denklem (2) rastgele değişkenin standart değişken haline getirilmesinde kullanılan eşitliği belirtmektedir (Spiegel, 1992).

$$
Z=\frac{\left(X-\mu_{x}\right)}{\sigma_{x}}
$$

\subsubsection{Gumbel Dağılımı}

Gumbel dağılımı (Ekstrem değer dağılımı); $X_{1}, X_{2}, X_{3}, \ldots, X_{n}$ şeklinde sıralanan örneklemde $\mathrm{n}$ tane rastgele değişkenin maksimum ve minimum değerlerin dağılımının modellenmesi olarak tanımlanmaktadır (Gumbel, 1958). Gumbel dağılımında $x$ değerine eşit ya da daha büyük değere sahip taşkın değerinin gerçekleşme olasılı̆̆ı $p$ aşağıda belirtilen Denklem (3) ile hesaplanabilmektedir.

$$
F(x)=p=1-e^{-e^{-y}}
$$


Denklem (3)’te belirtilen $y$, indirgenmiş değişken olarak adlandırılmakta ve aşağıdaki Denklem (4) ile elde edilmektedir:

$$
y=\left(x-x_{o}\right)
$$

Denklem (4)'te $x$; $p$ gerçekleşme olasılı̆̆ı olan taşkın debisini göstermektedir. Kullanılan veri serisinde eleman sayısına (N) göre $a$ ve $x_{o}$ değerlerini hesaplanmak için kullanılacak formül Denklem (5) ve Denklem (6)'daki gibi değişiklik gösterebilmektedir:

$$
\begin{aligned}
& N>30 \text { için } a=\frac{1.28255}{\sigma_{x}} \text { ve } x_{o}=\mu_{x}-0.45 \sigma_{x} \\
& N<30 \text { için } a=\frac{\sigma_{n}}{\sigma_{x}} \text { ve } x_{o}=\mu_{x}-\overline{Y_{n}} \frac{\sigma_{n}}{\sigma_{x}}
\end{aligned}
$$

Denklem (5) ve (6)'da belirtilen $a$; Denklem 5 ile hesaplanan sabit bir katsayıyı, $x_{o}$ ise dağılımın mod değerini temsil etmektedir. $\sigma_{\mathrm{n}}$ ve $\overline{Y_{n}}$ değerleri ise Fisher Trippett I tablosundan $\mathrm{N}$ değerine göre elde edilmektedir.

\subsubsection{Pearson Tip III Dağılımı}

Pearson Tip III dağılımında parametrelerin öngörülmesi; momentler veya maksimum olabilirlik yöntemleri ile gerçekleştirilebilir. Momentler yönteminde elde edilmesi gereken parametreler; ortalama $(\bar{x})$, standart sapma $(\bar{\sigma})$, çarpıklık katsayısı $\left(C_{S x}\right)$ ve dağılımın parametreleri olan $\alpha$, $\beta$ ve $x_{o}$ parametreleri arasındaki bağıntılar Denklem (7), (8) ve (9) ile bulunabilmektedir (Baykal ve Terzi, 2017):

$$
\begin{aligned}
& \bar{x}=x_{o}+\alpha \beta \\
& \sigma_{x}^{2}=\alpha \beta^{2} \\
& C_{s x}=\frac{2}{\sqrt{\alpha}}
\end{aligned}
$$

\subsubsection{Kolmogorov- Smirnov (K-S) Uygunluk Testi}

Hidrolojide olasılık dağılımlarının test edilmesinde sıklıkla kullanılan Kolmogorov- Smirnov (K-S) testi aşağıda gösterildiği üzere Denklem (10) ile hesaplanabilmektedir. Denklemde verilen $\mathrm{F}^{*}\left(\mathrm{x}_{\mathrm{i}}\right)$ gözlenen veri değeri Denklem 11 ile hesaplanırken, $\mathrm{F}\left(\mathrm{x}_{\mathrm{i}}\right)$ ise herhangi bir olasılık dağılımı ile hesaplanan veri değerini temsil etmektedir (Sandalc1, 2018). 


$$
\begin{aligned}
& D_{\max }=\left|F(x i)-F^{*}(x i)\right| \\
& F^{*}\left(x_{i}\right)=\frac{i}{N}
\end{aligned}
$$

\section{Bulgular ve Tartışma}

Ceyhan Nehri üzerinde bulunan 2004 ve 2020 nolu Misis ve Aslantaş AGİ'lere ait 2, 5, 10, 25, 50, 100, 200, 500 ve 1000 yıllık tekerrür periyoduna sahip taşkın debileri frekans analizi ve uygunluk testlerine göre hesaplanmaya çalışılmıştır. Normal dağılım, Gumbel ve Pearson Tip III dağılımları uygulanırken yıllık maksimum akım değerleri kullanılmış ve akım verilerine en uyumlu sonuçları ortaya koyan olasılık dağılımının belirlenmesi amacıyla K-S testinden yararlanılmıştır. Hesaplamalarda kullanılan yıllık toplam akımların istatistiksel parametreleri Tablo 2'de gösterilmektedir.

Tablo 2. AGI'lerin istatistiksel parametreleri (EİĖ, 2011)

\begin{tabular}{|c|c|c|c|c|c|c|}
\hline İstasyon No & $\mu_{x}$ & $\sigma_{x}$ & $C_{s x}$ & $\mu_{y}$ & $\sigma_{y}$ & $C_{s y}$ \\
\hline 2004 & 805 & 414.00 & 1.46 & 2.85 & 0.22 & -0.19 \\
\hline 2020 & 733 & 539.07 & 0.78 & 2.78 & 0.31 & 0.19 \\
\hline
\end{tabular}

2004 ve 2020 nolu istasyonlar için olasılık dağılım modelleri ile belirli tekerrür periyotlarında hesaplanan taşkın debi değerleri Tablo 3 'te verilmiştir. 25 yıllık tekerrür periyotuna kadar üç olasılık dağılımı ile elde edilen sonuçların birbirine yakın değerlerde olduğu gözlemlenmiştir. Bu nedenle 25 yıldan az tekerrüre sahip akım değerleri için üç olasılık dağılımından herhangi birinin taşkın analizi ve su yapılarının tasarım aşamaları için tercih edilebileceği yorumu yapılabilir.

Tablo 3. AGİ'ler için olasılık dağılımlarına göre hesaplanmış taşkın debi değerleri ( $\left.\mathrm{m}^{3} / \mathrm{s}\right)$

\begin{tabular}{|c|c|c|c|c|c|c|}
\hline \multirow{2}{*}{ Tekerrür Periyodu } & \multicolumn{2}{|c|}{ Normal Dağılım } & \multicolumn{2}{c|}{ Gumbel Dağılımı } & \multicolumn{2}{c|}{$\begin{array}{c}\text { Pearson Tip III } \\
\text { Dağılımı }\end{array}$} \\
\cline { 2 - 7 } & $\mathbf{2 0 0 4}$ & $\mathbf{2 0 2 0}$ & $\mathbf{2 0 0 4}$ & $\mathbf{2 0 2 0}$ & $\mathbf{2 0 0 4}$ & $\mathbf{2 0 2 0}$ \\
\hline $\mathbf{Q}_{\mathbf{2}}$ & 804.61 & 773.32 & 736.62 & 684.79 & 725.95 & 655.80 \\
\hline $\mathbf{Q}_{\mathbf{5}}$ & 1154.44 & 1228.83 & 1102.48 & 1161.18 & 1110.14 & 1195.14 \\
\hline $\mathbf{Q}_{\mathbf{1 0}}$ & 1335.36 & 1464.41 & 1344.72 & 1476.59 & 1359.79 & 1491.63 \\
\hline $\mathbf{Q}_{\mathbf{2 5}}$ & 1529.53 & 1716.69 & 1650.78 & 1875.12 & 1661.59 & 1844.19 \\
\hline $\mathbf{Q}_{\mathbf{5 0}}$ & 1655.38 & 1881.11 & 1877.84 & 2170.77 & 1881.02 & 2119.92 \\
\hline $\mathbf{Q}_{\mathbf{1 0 0}}$ & 1769.24 & 2029.36 & 2103.22 & 2464.24 & 2100.44 & 2367.35 \\
\hline $\mathbf{Q}_{\mathbf{2 0 0}}$ & 1870.67 & 2161.43 & 2327.78 & 2756.63 & 2302.47 & 2546.70 \\
\hline $\mathbf{Q}_{\mathbf{5 0 0}}$ & 1996.94 & 2325.85 & 2624.04 & 3142.39 & 2616.28 & 2959.79 \\
\hline $\mathbf{Q}_{\mathbf{1 0 0 0}}$ & 2079.74 & 2433.66 & 2847.94 & 3433.94 & 2768.64 & 3041.73 \\
\hline
\end{tabular}


Ancak tekerrür periyodu arttıkça; Normal dağılım ile elde edilen taşkın debilerinin Gumbel ve Pearson Tip III'e kıyasla daha düşük seviyelerde kaldığı görülebilmektedir. Şekil 2'de her iki istasyon için tekerrür periyotlarına göre debi değerleri grafikleri verilmektedir.

(a) 2004 Nolu $A G \dot{I}$

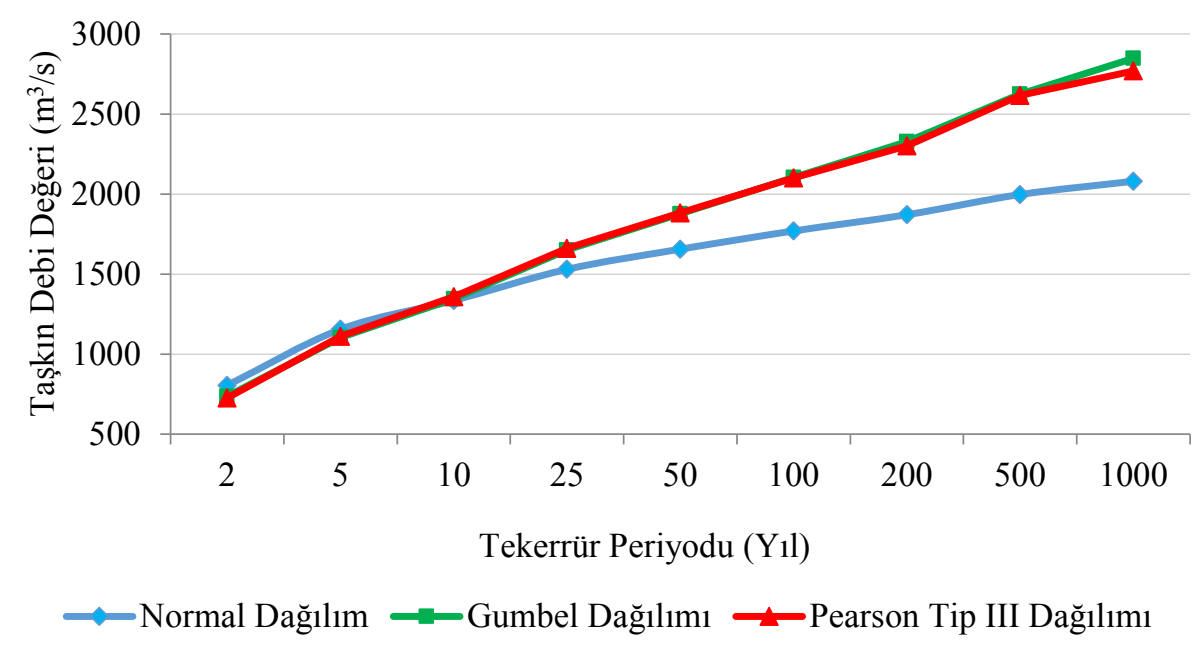

(b) 2020 Nolu $A G \dot{I}$

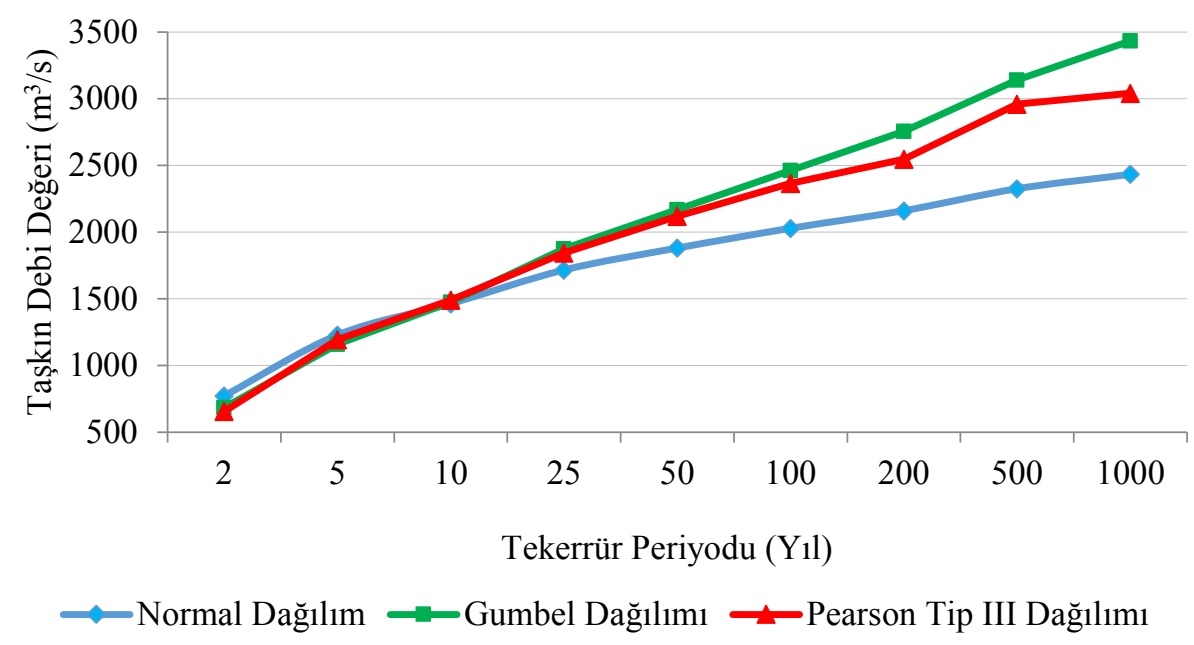

Şekil 2. Farklı tekerrür periyotlarına göre taşkın debisi değerleri

25 yıldan fazla tekerrüre sahip taşkın debileri incelendiğinde Aşık ve ark. (2004) yaptığı çalışma ile benzer olarak maksimum akım değeri Gumbel dağılımı; minimum akım değerleri ise Normal dağılım kullanılarak elde edilmiştir. Tercih edilen olasılık dağılımlarından en uygun olanın belirlenmesi için gözlenen ve beklenen değerlerin toplam frekansları arasındaki en büyük mutlak fark prensibine dayanan K-S testinden faydalanılmıştır (Tablo 4). Ayrıca Şekil 3'te K-S testi sonucu elde edilen ve gözlenen değerler arasındaki sapma miktarları görülebilmektedir. $\mathrm{y}=\mathrm{x}$ doğrusu tüm grafikler üzerinde gösterilmiş, farklı tekerrür periyotları için beklenen ve gözlenen değerlerin korelasyonunun bu doğruya ne kadar yakınsayabildiği irdelenmiştir. 
Tablo 4. 2004 ve 2020 nolu istasyonlar için Kolmogorov-Smirnov testi sonuçları.

\begin{tabular}{|c|c|c|c|c|}
\cline { 4 - 5 } \multicolumn{2}{c}{} & \multicolumn{2}{c|}{ Anlamlılı Yüzdeleri } \\
\hline \multirow{3}{*}{ Istasyon } & Dă̆ıllım Tipi & $D_{\max }$ & $\% 90$ & $\% 95$ \\
\hline \multirow{3}{*}{2004} & Normal Dağılım & 0.115 & Kabul & Kabul \\
\cline { 2 - 5 } & Gumbel Dağılım & 0.094 & Kabul & Kabul \\
\cline { 2 - 5 } & Pearson Tip III Dağılımı & $\mathbf{0 . 0 8 8}$ & Kabul & Kabul \\
\hline \multirow{3}{*}{2020} & Normal Dağılım & 0.115 & Kabul & Kabul \\
\cline { 2 - 5 } & Gumbel Dağılım & $\mathbf{0 . 0 9 4}$ & Kabul & Kabul \\
\cline { 2 - 5 } & Pearson Tip III Dağılımı & 0.104 & Kabul & Kabul \\
\hline
\end{tabular}

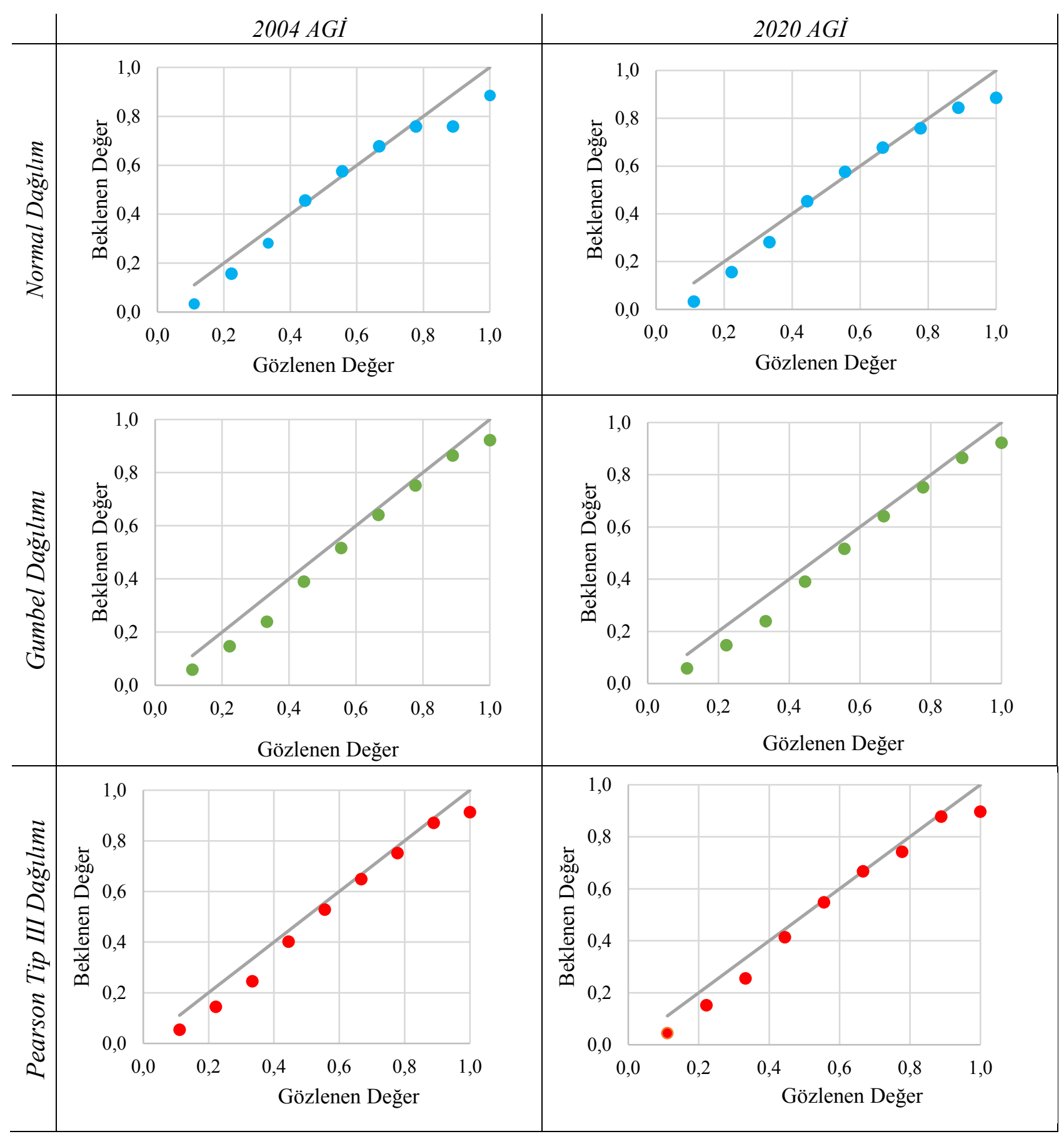

Şekil 3. Kolmogorov-Smirnov testi sonucu elde edilen ve gözlenen değerler arasındaki sapma miktarları $\left(D_{\max }\right)$ 
Üç olasılık dağılımı ile elde edilen taşkın debileri Denklem (10) ve Denklem (11) kullanılarak test edilmiştir. K-S testi sonucunda, kullanılan olasılık dağılımlarının 2004 ve 2020 nolu Misis ve Aslantaş istasyonlarının taşkın debisi tahmininde tercih edilebileceği gözlemlenmiştir. Şahin (2013) 2004 nolu AGİ için 1971-2000 yılları arasında ele aldığı frekans analizi çalışmasında 2, 5, 10, 25, 50 ve 100 yıllık tekerrür periyotları için K-S uygunluk testi ile birlikte yaklaşık \%85 benzer sonuçlar elde etmiştir. Tekerrür periyodu arttıkça yaklaşım yüzdesi daha çok artış göstermiştir. Bu çalışmada ilaveten 200, 500 ve 1000 yıllık dönüş aralığına göre taşkın debileri de tahmin edilmiştir. Ceyhan Nehri üzerinde konumlandırılmış 2020 nolu AGİ taşkın debileri için de aynı işlemler yapılmış ve farklı istasyon sonuçları da değerlendirilmeye çalışılmıştır. $\mathrm{D}_{\max }$ sapma değerleri göz önüne alındığında ise 2004 nolu AGİ için Pearson Tip III dağılımının, 2020 nolu istasyon için Gumbel dağılımının en uyumlu sonuçları verdiği tespit edilmiştir.

Şekil 3 değerlendirildiğinde; hem 2004 hem de 2020 AGİ için Normal dağılım verilerinde sapmalar dikkat çekmektedir. Bu doğrultuda Normal dağılımın belirlenen istasyon verileri için daha az uyuma sahip olduğu anlaşılmaktadır. Farooq ve ark. (2018) ile Acharya ve Joshi (2020) tarafından hidrolojik veriler üzerine yapılan çalışmalarda da, K-S testine göre en az uyumlu olasılık dağılımı Normal dağılım olarak tespit edilmiş, benzer sonuçlar elde edilmiştir. 2004 nolu AGİ için en az hata oranının Pearson Tip III, 2020 AGİ için ise Gumbel dağılımında olduğu gözlemlenmiş ve analitik yöntem ile elde edilen sonuçları destekler nitelikte olduğu belirlenmiştir. Kumar (2019) Nepal'de bulunan Rapti Nehri için yaptığı çalışmada Pearson Tip III olasılık dağılımının havza özelliklerini iyi bir şekilde temsil ettiğini belirtmiş olup, 2004 nolu istasyon için elde edilen sonuçlara yakın çıkarımların yer aldığı söylenebilir. Ayrıca Onen ve Bagatur (2017) ile Samantaray ve Sohoo (2020)'nin çalışmalarında inceledikleri tüm AGİ'ler için en yüksek debi değerlerini Gumbel dağılımı ile tahmin ettiklerini vurgulamaktadırlar. Paralel bir yaklaşımla bu çalışma açısından 2020 AGİ için de benzer ifadelerin ortaya konulabileceği açıktır.

\section{Sonuçlar ve Öneriler}

Artan nüfusla birlikte akarsu yataklarının kullanıma açılması sonucunda taşkınların kontrol altına alınması gün geçtikçe daha da önemli hale gelmektedir. Bu çalışmada Ceyhan Nehri üzerinde bulunan 2004 ve 2020 nolu akım gözlem istasyonlarının (AGI) Normal, Gumbel ve Pearson Tip III dağılımlarına göre taşkın frekans analizleri gerçekleştirilmiştir. Belirlenen istasyonlara ait yıllık maksimum akım değerlerinden elde edilen istatistiksel parametreler ile 2, 5, 10, 25, 50, 100, 200, 500 ve 1000 yıl gibi çeşitli tekerrür periyotlarındaki taşkın debileri hesaplanmıştır. Ayrıca olasılık dağılım fonksiyonlarından en uyumlu olanın belirlenmesi amacıyla taşkın debilerine Kolmogorov-Smirnov (K-S) testi uygulanmıştır. Yapılan test sonucunda 2004 nolu istasyon için Pearson Tip III, 2020 nolu 
istasyon için ise Gumbel olasılık dağılımının en uygun olduğu tespit edilmiştir. Sonuç olarak, taşkın debisi tahmini için kullanılan istatistiki yöntemler ve uygunluk testleri ilerleyen zamanlarda yapılması düşünülen köprü, menfez, dolusavak,...vb. su yapılarının tasarım aşamalarında rahatlıkla değerlendirilebilir. Çalışma sonuçları göz önünde bulundurularak, gelecekte yaşanması muhtemel taşkınların etkisini azaltabilmek adına yapısal ve yapısal olmayan önlemler de planlama süreçlerine dahil edilebilir.

\section{Yazarların Katkısı}

Tüm yazarlar çalışmaya eşit katkıda bulunmuştur.

\section{Çıkar Çatışması Beyanı}

Yazarlar arasında herhangi bir çıkar çatışması bulunmamaktadır.

\section{Araştırma ve Yayın Etiği Beyanı}

Yapılan çalışmada araştırma ve yayın etiğine uyulmuştur.

\section{Kaynaklar}

Acharya, B., ve Joshi, B. (2020). Flood frequency analysis for an ungauged Himalayan river basin using different methods: a case study of Modi Khola, Parbat, Nepal. Meteorology Hydrology and Water Management, 8(2), 46-51. https://doi.org/10.26491/mhwm/131092

Ahmad, U. N., Shabri, A., ve Zakaria, Z. A. (2011). Flood frequency analysis of annual maximum stream flows using L-moments and TL-moments approach. Applied Mathematical Sciences, 5(5), 243-253.

Anlı, A. S. (2006). Giresun Aksu Havzası maksimum akımlarının frekans analizi. Akdeniz Üniversitesi Ziraat Fakültesi Dergisi, 19(1), 99-106.

Aşık, Ş., Akkuzu, E., ve Karataş, B. (2004). Gediz Havzası akarsuları yıllık toplam akımlarına en uygun olasıl1k modelinin belirlenmesi. Ege Üniversitesi Ziraat Fakültesi Dergisi, 41(3), 177-184.

Ayaz, S., Aktaş, Ö., Erdoğan, N., Gürsoy, B. H., Atasoy, E., Aydöner, C., ve Akça, L. (2011). Havza bazında yüzeysel su kalitesinin değerlendirilmesi; örnek çalışma: Ceyhan Havzası. 1. Kıyı Bölgelerinde Çevre Kirliliği ve Kontrolü (KÇKK), Tekirdağ.

Bayazıt, M., ve Oğuz, E. B. Y. (2005). Mühendisler için istatistik. Birsen Yayınevi.

Baykal, T., ve Terzi, Ö. (2017). Küçük Aksu Çayı taşkın frekans analizi. Cumhuriyet Science Journal CSJ, 38(4), 639-646. https://doi.org/https://doi.org/10.17776/csj.348907

Bhagat, N. (2017). Flood frequency analysis using Gumbel's Distribution Method: A case study of Lower Mahi Basin, India. Journal of Water Resources and Ocean Science, 6(4), 51-54. https://doi.org/10.11648/j.wros.20170604.11

Bhat, M. S., Alam, A., Ahmad, B., Kotlia, B. S., Farooq, H., Taloor, A. K., ve Ahmad, S. (2019). Flood frequency analysis of river Jhelum in Kashmir basin. Quaternary International, 507, 288-294. https://doi.org/10.1016/j.quaint.2018.09.039

Black, A.R., ve Fadipe, D., (2009). Use of historic water level records for re-assessing flood frequency: Case study of the Spey catchment. Water Environ. J. 23, 23-31. https://doi.org/10.1111/j.17476593.2007.00105.x 
Chow, V.T., Maidment, D.R., ve Mays, L.W. (1988). Applied Hydrology. McGraw-Hill, International.

Elektrik İşleri Etüt İdaresi (EİEİ) (2011). Akım gözlem yıllıkları, Ankara.

Farooq, M., Shafique, M., ve Khattak, M.S. (2018). Flood frequency analysis of river swat using Log Pearson type 3, Generalized Extreme Value, Normal, and Gumbel Max distribution methods. Arab J Geosci 11, 216. https://doi.org/10.1007/s12517-018-3553-z

Gumbel, E.J. (1958). Statistics of Extremes. Columbia University Press. https://doi.org/10.7312/gumb92958

Kumanlığlu, A. A., ve Ersoy, S. B. (2018). Akım gözlemi olmayan havzalarda taşkın akımlarının belirlenmesi: Kız1ldere Havzası. Dokuz Eylül Üniversitesi Mühendislik Fakültesi Fen ve Mühendislik Dergisi, 20(60), 201-211. https://doi.org/10.21205/deufmd

Kumar, R. (2019). Flood frequency analysis of the Rapti River Basin using Log Pearson Type-III and Gumbel Extreme Value-1 Methods. Journal of the Geological Society of India, 94(5), 480-484. https://doi.org/10.1007/s12594-019-1344-0

Onen, F., ve Bagatur, T. (2017). Prediction of flood frequency factor for Gumbel distribution using Regression and GEP model. Arab J Sci Eng, 42, 3895-3906. https://doi.org/10.1007/s13369-017-2507-1

Özcan, E. (2006). Sel olayı ve Türkiye. Gazi Eğitim Fakültesi Dergisi, 26(1), 35-50.

Özcan, O. (2007). Sakarya Nehri Alt Havzası'nın taşkın riski analizinin Uzaktan Algılama ve CBS ile belirlenmesi. Yüksek Lisans Tezi, İstanbul Teknik Üniversitesi, Bilişim Enstitüsü, İstanbul.

Saka, F., Coşkun, H., Umarusman, H. B., Demirkol, M. R., Tanrıverdi, O., ve Katırcılar, R. (2019). Yıllık pik debiler için olasılık dağılımının belirlenmesi ve Giresun Aksu Deresi örneği. $\mathrm{http} / / /$ indexive.com/uploads/papers/pap_indexive15938694682147483647.pdf

Samantaray, S., ve Sohoo, A. (2020). Estimation of flood frequency using statistical method: Mahanadi River basin, India. $\mathrm{H}_{2}$ Open Journal, 3(1), 189-207. doi: 10.2166/h2oj.2020.004

Sandalc1, M. (2018). Flood frequency analysis of Akçay Stream. Sakarya University Journal of Science, 22(5), 1309-1313. https://doi.org/10.16984/saufenbilder.402190

Spiegel, M. R. (1992).Theory and problems of probability and statistics. New York: McGraw-Hill, pp. 109111.

Şahin, M. A. (2013). Regional flood frequency analysis for Ceyhan Basin. Yüksek Lisans Tezi, Orta Doğu Teknik Üniversitesi, Fen Bilimleri Enstitüsü, Ankara.

Şen, K., ve Aksu, H. (2021). İstanbul için standart süreli gözlenen en büyük yağışların eğilimleri. Teknik Dergi, 32(1), 10495-10514. https://doi.org/10.18400/tekderg.647558

Tanoue, M., Hirabayashi, Y., ve Ikeuchi, H., (2016). Global-scale river flood vulnerability in the last 50 years. Sci. Rep., 6, 36021. https://doi.org/10.1038/srep36021

Tarım ve Orman Bakanlığı (TOB), Su Yönetimi Genel Müdürlüğü (2018). Ceyhan Havzası taşkın yönetim planı. Ankara.

Üneş, F., Kaya, Y.Z., Varçin, H., Demirci, M., Taşar, B., ve Zelenakova, M. (2020). Flood hydraulic anayses: A case study of Amik Plain, Turkey. Water, 12(7), 2070. https://doi.org/10.3390/w12072070

Yavuz, A. A., ve Ergul, B. (2010). A study on the determining the best probability distribution for the annual average amount of water entering the Porsuk Dam. International Journal of Natural and Engineering Sciences, 4(3), 1-6.

Yılmaz, M., Tosunoğlu, F., ve Demirel, M. C. (2021). Taşkın frekansı analizinde klasik yöntemler ve alternatif bir parametre tahmin yönteminin karş1laştırılması. Journal of the Institute of Science and Technology, 11(2), 1243-1254. https://doi.org/10.21597/jist.805365

Yue, S., Ouarda, T.B.M.J., Bobée, B., Legendre, P., ve Bruneau, P., (1999). The Gumbel mixed model for flood frequency analysis. Journal of Hydrology, 226, 88-100.

Yüce, M. İ., ve Eşit, M. (2020). Ceyhan Havzasının kuraklık risk haritasının SPI ve SPEI metotları ile belirlenmesi. Su Kaynaklarl, 5(2), 1-8. 